\title{
UMA ANÁLISE DA PANDEMIA DE CORONAVÍRUS SOB O ENFOQUE DA BANALIZAÇÃO DO MAL DE HANNAH ARENDT
}

Simone Alvarez Lima*

\section{RESUMO}

A pandemia de coronavírus trouxe questões jurídicas e filosóficas, dentre elas, a banalização do mal. A naturalização das mortes, a possibilidade do médico escolher quem irá para um leito com respirador após a análise de um protocolo e a postura negacionista do Presidente da República mostram que os requisitos da banalização do mal, conceito criado por Hannah Arendt, estão presentes. A ética da solidariedade precisa ser relembrada, especialmente quando a sociedade contribui no aumento do contágio quando se aglomera ou pleiteia o inexistente direito de não usar a máscara.

Palavras-chave: Banalização do mal; Hannah Arend; coronavírus; pandemia; solidariedade

\section{AN ANALYSIS OF THE PANDEMIC OF CORONAVIRUS UNDER THE APPROACH TO THE BANALIZATION OF EVIL BY HANNAH ARENDT}

\begin{abstract}
The coronavirus pandemic brought legal and philosophical questions, among them, the trivialization of evil. The naturalization of the deaths, the possibility for the doctor to choose who will go to bed with a respirator after analyzing a protocol and the President of the Republic's denialist stance show that the requirements for the trivialization of evil, a concept created by Hannah Arendt, are present. The ethics of solidarity needs to be remembered, especially when society contributes to increasing contagion when the non-existent right not to wear the mask is crowded or pleads.
\end{abstract}

Keywords: Banalization of devil; Hannah Arendt; coronavirus; pandemic; solidarity

\section{INTRODUÇÃO}

Desde 20 de março de 2020, com a promulgação do Decreto $\mathrm{n}^{\circ}$ 6, o Brasil se encontra em estado de calamidade pública em virtude da pandemia de coronavírus (COVID-19), o qual tem um efeito devastador sobre o organismo humano e que já dizimou a vida de quase 200.000 .

\footnotetext{
* Doutora em Direito na linha de pesquisa Direitos Fundamentais e Novos Direitos pela Universidade Estácio de Sá. Especialista em Direito Internacional e Direito Constitucional. Professora da graduação em Direito e da pósgraduação em Filosofia e Sociologia na Universidade Estácio de Sá. E-mail: sissyalvarez22@ yahoo.com.br
} 
A pandemia colocou o Brasil diante de um problema filosófico e jurídico, que é até que ponto a conduta de uma pessoa pode impactar nos direitos da outra e em qual intensidade isso importa para aquele que está interferindo no direito alheio de não ser infectado.

Nem todas as pessoas parecem compreender a gravidade da doença e adotam posturas criticáveis frente à contenção da pandemia, tais como o Presidente da República, Jair Bolsonaro, e o Vereador de Porto Alegre, Valter Nagelstein. Por outro lado, os profissionais de saúde, que convivem com a doença no dia-a-dia, se viram na posição de escolher quem ficará com o leito de respirador.

Em virtude da morte ter se tornado normal a ponto de se virar motivo de ironia e de escolha, o presente artigo tem como objetivo dissertar sobre a relação entre o conceito de banalidade do mal de Hannah Arendt e a pandemia de coronavírus.

No primeiro item, será explicado o conceito de banalização do mal, tratado no livro Eichmann em Jerusalém, de Hannah Arendt, e o contexto em que ele foi formado, mostrando que o mal, especialmente quando amparado em instituições jurídicas e sociais, costuma ter o seu efeito nocivo banalizado.

No segundo item, são abordadas as condutas do Presidente da República, que demonstram uma postura negacionista da pandemia, do Vereador Valter Nagelstein, que fez piada com a doença e a situação extrema de escolher quem deveria ou não ir para o leito com respirador, que os médicos passaram a vivenciar em virtude do deficitário sistema brasileiro de saúde, que não estava preparado para suportar os efeitos da pandemia. Em todas as situações mencionadas vislumbra-se a concretização da banalização do mal.

Por fim, o último capítulo é dedicado a explicar a importância da responsabilidade sobre o outro, a fim de que a banalidade do mal permita que aqueles que não desejam usar a máscara não vejam os outros como homo sacers, ou seja, vidas que não merecem ser vividas. Neste item, também é destacado o fato de que uma postura solidária e ética, desde o início da pandemia, teria impedido que os números de infectados e de mortos pelo coronavírus não fossem tão grandes.

A relevância dessa pesquisa está em trazer um olhar filosófico sobre a pandemia de coronavírus, que auxilia a questionar atitudes e decisões de um modo além do jurídico, pois ainda que com base nas leis e em regulamentos, uma conduta pode não ser moral sob o ponto de vista da justiça, e convida ao leitor a refletir sobre a partir de quando e por quais motivos a morte alheia parou de incomodar e se tornou banal. 
Trata-se de uma pesquisa realizada sob o método dedutivo, em virtude de partir da conceituação de banalização do mal para tratar, especificamente, em seguida, de atitudes específicas que mostram o quão esse conceito de Hannah Arendt se encontra presente na sociedade brasileira.

\section{DO CONTEXTO DA TEORIA DA BANALIZAÇÃO DO MAL}

Hannah Arendt foi uma cientista política que não concordava quando a chamavam de filósofa. Nascida na Alemanha, em 1906, judia, Hannah viveu durante o período do nazismo e escreveu famosas obras como As Origens do Totalitarismo, A Condição Humana, Homens em Tempos Sombrios, Eichmann em Jerusalém, dentre outras. (BOWDOW, 2019, p. 25)

Hannah Arendt viveu os horrores do nazismo alemão, perdeu sua cidadania alemã e precisou se mudar para os Estados Unidos a fim de se proteger, onde escreveu sobre esse regime totalitário e, dentre seus escritos, um deles se dedicou ao julgamento de Adolf Eichmann.

Adolf Eichmann foi um dos soldados nazistas, com a responsabilidade de dirigir o transporte que levava os judeus para os campos de concentração onde morreriam. Anos depois do fim do nazismo, Eichmann foi capturado por Israel, na Argentina, que o levou para o território israelense para julgá-lo pelas atrocidades nazistas. Oliveira (2014, p. 93) explica que, em 1960, em Buenos Aires, um comando israelense sequestrou e embarcou num avião de carga, com destino a Tel-Aviv, Adolf Eichmann. Em 1961, ocorreu o seu julgamento e Hannah Arendt se ofereceu para cobrir o evento, na qualidade de repórter ao jornal New Yorker e escreveu sobre a aparente "cotidianidade" dele, que o fazia não parecer o monstro que ele foi no passado.

Arendt utiliza essa expressão ao enfrentar cara a cara Eichmann no seu julgamento. Assim como outros, foi à sala do Tribunal à espera de encontrar uma mente brilhante no seu delírio de onipotência, talvez um sádico ou um demônio furibundo, quase uma das grandiosas personagens malignas de Shakespeare. Nada disso aconteceu. Era um homem normal, nada tinha de extraordinário. Não havia uma ligação entre a figurinha daquele indivíduo e a magnitude dos crimes que cometera. (SÁNCHEZ, 2015, p. 124) 
Hannah Arendt não era uma judia tradicional, pois sua família também não o era, o que fez com que ela tratasse o julgamento de Eichmann com mais neutralidade do que qualquer outro judeu o faria, o que desagradou a população judia. A filósofa concluiu que os regimes totalitários não produzem monstros, mas, sim, pessoas incapazes de pensar por si mesmas "e incapazes de compreender a imoralidade das suas ações, visto que tudo o que faziam era sancionado pela lei e apoiado pelo regime vigente.” (FRY, 2017, p. 45)

O mal não era trivial porque não era importante, mas porque ocorria sem intenção diabólica por parte do agente que o cometia, tal como Adolf Eichmann, o qual apenas obedecia às ordens de Adolf Hitler, permitindo que a ideologia nazista tomasse decisões no seu lugar, o que o levou a se distanciar das consequências de suas decisões. Por esse motivo, Hannah Arendt julgou Eichmann como um homem pouco inteligente e sem capacidade de olhar para qualquer coisa e foi, justamente, essa inaptidão, que levou à sua disposição para participar das práticas brutais dos nazistas. (FRY, 2017, p. 46)

Eichmann repetidamente dizia em seu julgamento:

Com o assassinato de judeus não tive nada a ver. Nunca matei um judeu, nem um nãojudeu- nunca matei nenhum ser humano. Nunca dei uma ordem para matar, fosse um judeu, fosse um não-judeu; simplesmente não fiz isso." Ele não deixou dúvida de que teria matado o próprio pai se houvesse recebido ordem nesse sentido. Por isso, ele repetia, incessantemente (...) que só podia ser acusado de "ajudar e assistir" à aniquilação dos judeus, a qual, declara ele em Jerusalém, fora um dos "maiores crimes da história da Humanidade. (ARENDT, 1999, p. 33).

Ressalta-se que o título "banalidade do mal” foi criticado, pois os críticos entenderam que ela dizia que o mal do nazismo era banal, mas, na verdade, ela apenas quis se referir que Eichmann estava cumprindo ordens ditadas por um Estado soberano, o que levava à sensação de que aquilo não era uma maldade, e, sim, mera obediência às ordens superiores. Arendt (1999, p. 62) afirmou que "quanto mais se ouvia Eichmann, mais óbvio ficava que a sua incapacidade de falar estava intimamente relacionada com a sua incapacidade de pensar do ponto de vista de outra pessoa."

Hannah Arendt não via nada de especial em Eichmann, apenas o fato de que ele fazia parte de um esquema de aniquilação de milhões de pessoas (SANCHÉZ, 2015, p. 124).

Eichmann declarou, no tribunal, ser kantiano porque apenas estava cumprindo o seu dever, e, por isso, sua ação estava conforme a moral. Sanchéz (2015, p. 123) conta que Eichmann afirmava que não só obedecia a ordens, mas obedecia à lei de Hitler como supremo 
legislador. Agia de acordo com o que considerava ser exigência de seu dever de cidadão cumpridor da lei. Só que o que Kant (1995, p.36), ensinava era que "o mais alto valor moral consiste em fazer o bem, não por inclinação, mas por dever."

\begin{abstract}
Durante o interrogatório, Eichmann declarou, repentinamente, e com grande ênfase, que sempre vivera de acordo com os preceitos morais de Kant, em especial com a definição kantiana de dever. Essa afirmação era revoltante e também incompreensível, já que a filosofia moral de Kant está tão intimamente ligada à faculdade humana de julgar que elimina totalmente a obediência cega. (ARENDT, 1999, p. 90)
\end{abstract}

Hannah Arendt apontou que Eichmann era um tipo de criminoso moderno, pois utiliza as técnicas específicas de sociedades modernas, tais como a burocracia, a ideologia e o conformismo. Tudo isso se torna atual quando se reflete filosoficamente a respeito da gestão da pandemia de coronavírus. Nunca, neste século XXI, se falou tanto sobre o princípio da legalidade insculpido no art. $5^{\circ}$, II da Constituição Federal, que prevê que "ninguém será obrigado a fazer ou deixar de fazer alguma coisa senão em virtude de lei."

O objetivo de se amparar no princípio da legalidade a fim de não usar máscara nas ruas mostram o quão não importa fazer o mal ao próximo se isso estiver amparado na legislação. Muitas pessoas têm agido como Eichmann, tendo em vista que não são, necessariamente, diabólicas, com uma mente brilhante a fim de perpetrar o mal, mas que se amparam na legislação para justificar uma conduta que pode ajudar na disseminação de um vírus mortal que está perto de alcançar o patamar de 200 mil mortes.

\footnotetext{
Habitamos o mesmo planeta, mas temos condições absolutamente desiguais de vida e, portanto, de reação a pandemias. Quem não tem casa, não pode fazer isolamento físico. Quem não tem trabalho, não consegue se alimentar adequadamente, não tem saneamento básico e, portanto, não terá as condições para enfrentar o vírus e a doença. A doença não atingirá nossos corpos da mesma maneira. E mesmo que tenha sido disseminada entre pessoas privilegiadas que viajam em aviões, muitas das quais fatalmente atingidas por seus efeitos, o fato é que a doença fará muito mais vítimas entre os vulneráveis, que são a maioria, especialmente em países recordistas em desigualdade como o Brasil. Diante de tantas constatações, cada vez mais visíveis e irrecusáveis, a COVID-19 deveria nos impedir de seguir fingindo que a desigualdade social é uma fatalidade, em relação a qual não temos responsabilidade alguma. (SEVERO, 2020)
}

Se uma pessoa não teme os malefícios do coronavírus e nem o risco de vida que ele traz para si, é válido que pense sobre os efeitos do vírus sobre o organismo dos demais seres humanos, afinal, a gravidade não é a mesma para todas as pessoas, afinal, há os assintomáticos e as pessoas que falecem em poucos dias após o contágio. 
Em uma pandemia, é necessário pensar além do que o ordenamento jurídico oferece, afinal, muitas das normas foram criados em um momento de paz, não estando preparado para amparar todas as situações jurídicas oriundas de uma calamidade pública. Nas palavras de Sandel (2017, p. 144), "se agirmos por qualquer outro motivo que não seja o dever, como o interesse próprio, nossa ação não terá valor moral.” Logo, a ausência de regulamentação jurídica específica para um caso de pandemia somado ao egoísmo da sociedade tem levado à morte milhares de pessoas.

Assim, o próximo item é dedicado a abordar questões polêmicas sobre a gestão da Covid-19 no Brasil, no tocante ao negacionismo e ao protocolo orientador da escolha médica em que é possível verificar o ressurgimento da teoria da banalização do mal no Brasil.

\section{DA GESTÃO DA PANDEMIA DE CORONAVÍRUS NO BRASIL}

Alguns episódios da pandemia de coronavírus têm servido para relembrar a expressão banalização do mal, criada por Hannah Arend. No presente momento, o Brasil conta com quase 200.000 mortes em virtude da COVID-19, ou seja, quase 200.000 famílias foram destruídas e sonhos finalizados, ocasionando sofrimentos em virtude de uma doença contra a qual ainda não existe vacina e que demanda uma quantidade de leitos com respiradores que o Brasil não possui.

Em primeiro lugar, é relevante destacar algumas atitudes do Chefe do Poder Executivo Federal. Em diferentes momentos, o Presidente Jair Bolsonaro teve condutas reprováveis sob o ponto de vista jurídico e moral, tais como o questionamento a respeito do fechamento de escolas porque o grupo de risco era formado por idosos (BRASIL, 2020), ignorando que tais crianças e adolescentes, ao voltar para casa, contaminavam seus familiares idosos, não utilização da máscara, estímulo a aglomerações.

Além disso, o Presidente afirmou que devido ao seu "histórico de atleta", não se preocupava em contrair o coronavírus, pois, seria apenas uma "gripezinha". (BETIM, 2020) Tal fala mostra o quanto ele sempre minimizou os efeitos da doença, cooperando para disseminar a ideia errônea de que o coronavírus não era grave, mas, sim, apenas uma histeria social. 
Em 29 de março de 2020, Jair Bolsonaro defendeu a volta da população ao trabalho e ainda afirmou que pretendia elaborar um decreto para que a população volte a trabalhar. Em suas palavras, "se o Brasil continuar tendo seus empregos destruídos, vocês vão ver a desgraça que vai se abater sobre o país." (ESTADÃO, 2020) Mais do que isso, iniciou uma campanha orçada em cerca de 5 milhões, com o slogan “o Brasil não pode parar”, a qual foi promovida sem o aval do Ministério da Saúde. (REUTERS, 2020)

Em 20 de abril de 2020, quando um jornalista questionou o Presidente da República sobre a quantidade de mortes, ele respondeu: “e daí? Não sou coveiro". E, também, comentou “aproximadamente $70 \%$ da população vai ser infectada. Não adianta querer correr disso. É uma verdade. Estão com medo da verdade? Levaram o pavor para o público, histeria. E não é verdade. Estamos vendo que não é verdade. Lamentamos as mortes, e é a vida. Vai morrer.” (GOMES, 2020)

Em referência ao seu próprio nome, o Presidente da República mencionou: "Eu sou Messias, mas não faço milagre.” Esse tipo de mensagem ridiculariza a morte, que, apesar de ser o fim de todos os seres vivos, logo, um fato natural da vida, não deve ser banalizado, especialmente quando quem fala é o maior representante da nação brasileira, que é o Presidente da República. A esse respeito, é válido trazer o entendimento de Correa:

\footnotetext{
A morte é um fim natural da vida humana. Finitude natural, mas não por isso pode ser banalizada ou ridicularizada. A morte deve ser consequência de uma vida vivida em plenitude, direito de todas e todos independente de origem, raça, gênero, idade, situação econômica, política e/ou social. Os familiares, amigos e amigas, e pessoas acometidas pelo coronavírus merecem respeito, sejam elas próximas a nós ou estejam em qualquer parte do mundo. (CORREA, 2020)
}

Além do Presidente da República, o Vereador Valter Nagelstein, de Porto Alegre, gravou uma brincadeira na qual ele e a sua família dançavam ao redor do que seria uma vítima de Covid-19, em um simulado velório. As reações foram negativas, como, por exemplo "isso mostra bem a cara de quem não desce dos carros e convoca o povo pra ir pra rua." (LEIA JÁ, 2020)

Utilizando-se de seu poder constitucional de vetar previsto no art. 84, V da atual Constituição, o Presidente da República desobrigou a utilização da máscara em estabelecimentos comerciais, industriais, templos religiosos e estabelecimentos de ensino, vetando o art. $3^{\circ}, \S 3^{\circ}$ da Lei $n^{o} 14.019$, de 02 de julho de 2020, que dispõe sobre a obrigatoriedade do uso de máscaras de proteção individual para circulação de pessoas em espaços públicos e privados acessíveis ao público. 
Esse veto demonstra a despreocupação com a saúde pública, eis que tirou a obrigatoriedade do uso da máscara em locais de grande circulação, estimulando condutas agressivas por parte de pessoas que teimavam em circular sem o acessório, e o aumento do número de casos de contaminação.

O Sistema de Saúde brasileiro não é suficiente para conceder leitos com respiradores a todos que necessitam e os médicos ficam diante da difícil escolha a respeito de quem irá salvar. O que os médicos chamam de "tirar o peso da escolha de Sofia", na realidade, é a manifestação mais atual sobre a banalidade do mal abordada por Hannah Arendt, afinal, chegou-se a um protocolo para orientar a quem se deve salvar.

A expressão escolha de Sofia provém de um caso em que uma mulher teve que escolher dentre seus dois filhos, qual ela salvaria em um campo de concentração nazista durante a Segunda Guerra Mundial. Atualmente, quando alguém está diante de uma escolha difícil, diz que tem que fazer a escolha de Sofia.

A ausência de um protocolo que servisse como guia de conduta sobre quem salvar, forçava o médico a raciocinar para escolher alguém, fazendo-o com que ele se sentisse culpado pela vida ceifada daquele que não foi escolhido, culpa esta, que, na verdade, é de um sistema político corrupto que, costumeiramente, desvia dinheiro que poderia ter sido investido na saúde.

O protocolo elaborado no Estado do Rio de Janeiro criou uma avaliação de pacientes que somariam notas de 0 a 24, no qual o médico deveria considerar funcionamento de órgãos como pulmões, rins e coração; se o paciente possui doenças preexistentes, como diabetes e hipertensão; idade, sendo que o jovem teria prioridade. Quanto menor a pontuação, mais chance teria a pessoa de receber o tratamento médico necessário e, de modo inverso, quanto maior a pontuação, mais o paciente chances de ficar no final da fila de atendimento, o que, acarretaria a provável morte deste que foi preterido. (TV GLOBO, 2020)

Em outras palavras, salvar-se-ia aquele paciente que tem maior utilidade social e chance de sobreviver. Em contrapartida, a pessoa mais fragilizada, mais idosa e que mais está sofrendo, seria entregue à própria sorte, ou melhor, à morte. Por mais cruel que isso pareça, na realidade, servia para tirar o peso da escolha, não apenas do profissional de saúde, mas de todo um sistema de saúde deficitário. Uma vez que a escolha estivesse suportada em um protocolo, ainda que a decisão gerasse a morte alguém, isso seria mais aceitável e o médico seria apenas o executor do que foi estabelecido por um órgão superior. 
Assim, em virtude de um protocolo que orienta a escolha sobre quem deve ser escolhido pelo médico para ir para o leito com respirador, que se livra da necessidade de racionalização, somada à postura negacionista do Presidente da República, todas as condições para a banalização do mal encontram-se reunidas, quais sejam:

\footnotetext{
Elementos internos ao sujeito: ausência de fatores subjetivos, que se concretiza na ausência da capacidade de julgar e de pensar;

Elementos externos, mas que possibilitam e favorecem a ausência do pensamento: agir dentro de um sistema hierárquico e burocrático;

Forma do mal: tem um caráter cotidiano e rotineiro. Insere-se em um esquema de trabalho. Não é uma explosão de violência tumultuosa. (SANCHÉZ, 2015, p. 127)
}

Assim, verifica-se que, desde a Presidência da República aos agentes de saúde há a propagação da banalização do mal. Não se critica os médicos, pois eles não são responsáveis pelo caos na saúde brasileira, mas, sim, a consequência deste caos, que é a institucionalização de uma escolha que não deveria existir, afinal, todas as vidas importam, independentemente da idade e da fragilidade dos órgãos.

Agora, perceba isso sob o ponto de vista kantiano, o qual é um filósofo favorável ao universalismo dos direitos humanos e contra decisões utilitaristas. Para Kant (1995, p. 71), "no reino dos fins, tudo tem ou um preço ou uma dignidade. Quando uma coisa tem um preço, pode pôr-se em vez dela qualquer outra como equivalente; mas quando uma coisa está acima de todo o preço, não permite equivalente, então ela tem dignidade."

Os não escolhidos, que, provavelmente, irão morrer, não poderão ser jamais substituídos dentro de suas famílias e isso mostra que eles não têm um preço, mas um valor. Seriam essas pessoas que teriam a vida ceifada. Entretanto, isso não seria uma maldade, eis que amparada em um protocolo.

O Presidente Jair Bolsonaro busca, até hoje, normalizar o que é um total estado de anomia, utilizando-se de suas competências para vetar o que deveria ser obrigatório e estimular condutas, como aglomerações e o não uso da máscara que leva à disseminação do coronavírus.

\section{DA RESPONSABILIDADE SOBRE O OUTRO}

Ainda que não seja verbalizado, não há como negar que um apelo chega à consciência 
de cada um para a auto preservação a fim de que isso impacte sobre as demais vidas. Cada um que respeita a quarentena, tem o poder de não infectar diversas pessoas. Claro, nem todas as pessoas podem permanecer dentro de casa pois precisam trabalhar e, para esses casos, o uso da máscara é essencial.

nós somos aquilo que respondemos ao apelo do Outro. Apelo falado ou mudo. Apelo que nos chama a sermos aquilo que respondemos, mesmo quando ignoramos o Outro, mesmo quando negamos atender o que se pede. Somos sempre essa resposta, pois somos responsáveis por ela. Somos, pois, essa responsabilidade. (CRUZ, 2015, p. 155)

A resposta à pandemia, tanto por parte do Presidente da República, Jair Bolsonaro, quanto por parte de parcela da sociedade que permaneceu relutante ao uso da máscara, deveria ser dada a partir da ética da alteridade, na qual o apelo do Outro seria escutado e respondido, no lugar de ser ignorado em nome de interesses próprios.

A resposta deveria ser dada de acordo com a necessidade alheia, ou seja, daquelas pessoas que, ao voltarem para suas casas, encontrassem seus parentes pertencentes aos grupos de risco. A responsabilidade de cada um sobre o Outro leva as pessoas a refletirem sobre o que, de fato, entendem sobre dignidade humana, igualdade, direitos humanos e, sobretudo, respeito.

De acordo com a Organização Mundial da Saúde, é necessário que os países adotem medidas profiláticas e o Ministério da Saúde recomenda o uso da máscara. A Lei no 13.979/2020 dá a liberdade para que as autoridades locais adotem as medidas necessárias para a contenção da pandemia e Governadores e Prefeitos obrigaram a utilização da máscara.

Em diversos Estados foram promulgadas legislações referentes ao uso da máscara, tais como São Paulo, por meio do Decreto Estadual n 64.949; Rio de Janeiro, por meio do Decreto Estadual no 47.060; Ceará, pelo Decreto Estadual n³3.608; Amazonas, pelo Decreto Estadual $\mathrm{n}^{\circ}$ 42.278, etc. Assim, em virtude do decreto ser uma lei, é possível que as pessoas sejam obrigadas a usar a máscara porque a obrigação é oriunda de lei.

Um autor que dialogaria com Hannah Arendt a respeito das consequências da banalização do mal é Giorgio Agamben, o qual fez apontamentos a respeito do que ele considera homo sacer, ou seja, aquela pessoa que padece de uma dupla exclusão, se por um lado, é possível matar esta pessoa sem ilicitude, por outro lado, esta mesma pessoa não é considerada de valor para ser utilizada em um sacrifício sagrado, sendo dispensada tanto pela lei natural quanto pela lei divina. O termo sacer se refere à vida matável. 
A vida de uma pessoa idosa não é menos valorosa do que a de um jovem, especialmente se for utilizar o argumento de que direitos humanos são universais e ninguém perde o direito à vida quando atinge determinada idade ou quando adquire alguma comorbidade. Sob o ponto de vista jurídico, não há como negar que protocolos que orientam a escolha de um médico na hora de escolher quem irá para o leito com respirador com base nos critérios supramencionados são atentatórios aos direitos humanos, restando, para debates, os aspectos filosóficos.

Em poucas linhas, pode-se dizer que a banalidade do mal tem o condão de torar os seres humanos não escolhidos os atuais homo sacers. Nas palavras de Agamben (2014, p. 83), "no caso do homo sacer, uma pessoa é simplesmente posta para fora da jurisdição humana sem ultrapassar para a divina." Este assassinato não seria considerado nem homicídio e nem sacrifício.” Ora, quando o Presidente da República veta a obrigatoriedade do uso da máscara em lugares de grande circulação, ele está ajudando na disseminação do vírus, ao invés de colocar em prática os ditames do art. 196 da Constituição Federal, que estabelece que "a saúde é direito de todos e dever do Estado, garantido mediante políticas sociais e econômicas que visem à redução do risco de doença e de outros agravos e ao acesso universal e igualitário às ações e serviços para sua promoção, proteção e recuperação."

Quanto menos pessoas usam a máscara, mais pessoas são contaminadas. O Sistema brasileiro de saúde pública e particular não conseguem receber todos os doentes e interná-los devidamente, logo, a consequência da dispensa da máscara é o colapso do sistema, o qual precisará de protocolos que justificarão a privação da vida, ou seja, ampararão a escolha do homo sacer. Tendo em vista a fundamentação, o mal estará banalizado.

Agamben (2014, p. 127) explica a característica da atual biopolítica, que é a necessidade de redefinição contínua sobre o que articula e separa o que está dentro e o que está fora, possuindo uma linha que deve ser incessantemente redesenhada. No caso em estudo, a realidade é que desde o advento do Direito Internacional dos Direitos Humanos, o Brasil nunca passou por uma pandemia e, por isso, o redesenho da linha que separa o que está dentro ou fora, ou seja, quem terá acesso ao respirador e quem não o terá, esteja sendo feito de modo utilitarista, ou seja, pensando em quem terá mais possibilidade de viver, não em quem está mais debilitado.

Assim como Eichmann não odiava os judeus, os médicos não odeiam os pacientes que optaram por não salvar, e nem as pessoas que colocam em risco a vida de outras quando se recusam a usar a máscara, também não odeiam os prováveis infectados pela sua conduta. $\mathrm{O}$ 
próprio Presidente da República quando vetou a obrigatoriedade do uso da máscara também não fez isso porque odeia alguém especificamente.

A luta pela banalização do mal chegou ao Poder Judiciário, entretanto, o autor da ação não logrou êxito. Em 30 de julho de 2020, no mandado de segurança $n^{\circ}$ 501234169.2020.8.24.0020/SC, o juiz proferiu uma decisão que desagradou o autor que desejava andar livremente sem máscara, alegando ilegalidade e inconstitucionalidade de normas municipais que obrigam o uso da máscara sob pena de multa.

Fosse o impetrante o último e único indivíduo morador de Criciúma (ou afinal o último habitante do planeta, uma vez que se cuida de pandemia e como o próprio nome sugere trata-se de uma epidemia global) não haveria o menor problema para que o mesmo circulasse livremente sem máscara e ficasse exposto ao vírus Covid-19 (ou a qualquer outra moléstia letal transmissível) por sua livre e espontânea vontade, uma vez que não transmitiria seus males para quem quer que seja. Mas não é esta a realidade. (MS 5012341-69.2020.8.24.0020/SC. Decisão em:30 de julho de 2020)

O juiz da $2^{\text {a }}$ Vara de Criciúma considerou que o Brasil vive um momento excepcional e que a máscara não é para mera proteção individual, mas, também, um instrumento de proteção ao outro. O impetrante não é imune ao vírus e, por isso, passível de ser contaminado, logo, por questão de ética individual e coletiva, esta última no tocante à proteção de sua família, vizinhos, amigos e todos que cruzarem com ele.

Por mais que a máscara seja recomendada pela Organização Mundial da Saúde, pelo Ministério da Saúde e por médicos, muitas pessoas relutam em utilizá-la, argumentando que a imposição fere seus direitos individuais, especialmente, os relacionados à liberdade, voltados para a proteção do indivíduo em face do Estado, cuja inspiração adveio das ideias libertárias do Iluminismo. (BARROSO, 2019, p. 493)

Ao escrever sobre como Kant entendia a liberdade, Sandel (2017, p. 140) inicia afirmando que "com frequência definimos liberdade como ausência de obstáculos para que possamos fazer o que quisermos. Kant discorda. Ele tem uma definição mais estrita e rigorosa de liberdade."

Ao ver de Kant, é necessário que haja autonomia para que haja responsabilidade moral. Perceba que se uma pessoa cai de uma janela, seu movimento é guiado pela força da gravidade, não havendo nenhuma autonomia nisso, logo, se uma morte acontece devido a queda da pessoa, não há responsabilidade sobre esta outra morte, afinal, não havia possibilidade para a pessoa, 
que caiu de um prédio, escolher cair em outro lugar porque não tem como guiar os seus movimentos. Por outro lado, se há liberdade de escolha, há que se falar em responsabilização moral.

A banalização do mal por meio de critérios para praticá-lo faz com que o médico se distancie emocionalmente da escolha a ser tomada, eis que amparada em um sistema institucional. De outro lado, a banalização do mal por meio da dispensa do uso de máscaras leva a muitas pessoas a se negarem a usar a máscara alegando que não são obrigadas, afinal, a Lei $n^{\circ} 14.019 / 2020$ as dispensam de uso em outros lugares, como se essa conduta não colocasse a saúde a vida do outro em risco.

A pandemia de coronavírus veio para mostrar o quão podem ser responsáveis as pessoas pela vida das demais. A conscientização, a solidariedade e a ética teriam sido primordiais para que o número de mortes não fosse tão elevado. De acordo com dados da Oxfam Brasil (2020), "a insuficiência de leitos, de respiradores e testes, a falta de médicos e de 
enfermeiros, a exposição de profissionais de saúde a riscos e as condições inadequadas de trabalho são mais letais do que o coronavírus, para o qual não há tratamento ou vacina."

\section{CONCLUSÃO}

O presente artigo permite concluir que na gestão brasileira da pandemia do coronavírus no Brasil há todos os elementos presentes da banalização do mal, conceito trazido por Hannah Arendt quando ela, ao testemunhar o julgamento de Adolf Eichmann, percebeu que o mal nem sempre assume um caráter de monstruosidade.

Quando Hannah Arendt afirm o u que o mal não possui raízes profundas é porque, muitas vezes, ele é fruto de uma ação irracional, em que não há subjetividade, ou seja, algo contra a pessoa contra quem está se fazendo mal, e é isso o que tem acontecido no Brasil desde que o país entrou em estado de calamidade pública.

O Presidente Jair Messias Bolsonaro foi criticado por sua postura negacionista em relação à gravidade do coronavírus, o que foi verificado em diversas falas noticiadas, como que a pandemia se trata de uma mera gripezinha, que as pessoas devem voltar ao trabalho em virtude do eventual colapso à economia e por meio de atitudes, como a utilização de seu poder de veto para desobrigar a utilização da máscara em locais de alta rotatividade.

Todo o sistema de corrupção brasileiro fez com que os hospitais fossem deficitários para atender a demanda de pessoas com necessidade de utilização de respiradores, levando para os médicos a difícil escolha de saber quem será salvo. Para amenizar essa situação foi criado um protocolo que orienta a escolha e, em síntese, o escolhido à salvação será mais jovem ou o mais saudável.

A partir do momento em que há um protocolo, não há mais o que raciocinar, eis que a escolha agora se dará por pontuação. Além disso, a externalidade da conduta, uma vez que a decisão não é mais do médico, em conjunto ao cumprimento de um dever formam os elementos pertencentes à banalização do mal. Agora não há mais uma opção feita por uma pessoa, mas, por um sistema superior a ela, entretanto, a consequência maléfica é a mesma: a morte da pessoa preterida. A dor da escolha se dilui a partir do momento em que ela é institucionalizada. 
Por fim, a sociedade, com amparo na legislação que desobriga o uso da máscara em diversos lugares, sente-se no direito de se expor e de expor as demais pessoas à contaminação por coronavírus, o que parece que a morte, tão rotineira, se tornou tão normal, que muitos não temem ser o transmissor da doença, ou, pelo menos, não se reconhecem como potenciais disseminadores da doença. A maior prova de falta de solidariedade foram os diversos mandados de segurança que foram impetrados a fim de lutar pelo inexistente direito líquido e certo de não usar a máscara. Nem mesmo os direitos fundamentais são absolutos quando entram em choque com o direito alheio.

Nunca a frase "a morte é sempre do outro" teve tanta adequação ao Brasil como agora, em um momento em que o Presidente da República, o Vereador e a sociedade chegam ao ponto de fazer piada com a morte, desprezando o fato de que quase 200 mil famílias foram destruídas desde que a pandemia chegou ao país. Fica o alerta de que a externalidade da conduta e a cotidianidade da morte não devem ser motivo para que não nos importemos mais com a morte alheia, afinal, nunca será possível saber quando o fim chegará em nossos lares.

\section{REFERÊNCIAS}

AGAMBEN, Giorgio. Homo sacer: o poder soberano e a vida nua I. Tradução de Henrique Burigo. 2. ed. Belo Horizonte: UFMG, 2014.

ARENDT, Hannah. Eichmann em Jerusalém: um relato sobre a banalidade do mal. Tradução: José Rubens Siqueira. 14. Ed. São Paulo: Companhia das Letras, 1999.

BARROSO, Luís Roberto. Curso de Direito Constitucional Contemporâneo. 8. Ed. São Paulo: Saraiva, 2019.

BETIM, Felipe. Sobe para 23 o total de pessoas que estiveram com Bolsonaro nos EUA e tem coronavírus. Disponível em: https://g1.globo.com/politica/noticia/2020/03/23/sobe-para23-o-total-de-pessoas-que-estiveram-com-bolsonaro-nos-eua-e-tem-coronavirus.ghtml.

Acesso em: 07 de abril de 2020.

BOWDON, Tom Butler. 50 clássicos da Filosofia. São Paulo: Benvirá, 2019.

BRASIL 247. Ignorante, Bolsonaro pergunta: porque fechar escolas, se idosos são grupo de risco? Disponível em: https://www.brasil247.com/brasil/ignorante-bolsonaro-pergunta-porque-fechar-escolas-se-idosos-sao-grupos-de-risco. Acesso em: 07 de abril de 2020.

CORREA, Michele. A banalidade do mal. Disponível em: https://www.brasildefators.com.br/2020/04/07/artigo-a-banalidade-do-mal. Acesso em: 30 de julho de 2020. 
CRUZ, Álvaro Ricardo de Souza. (O) Outro (e) (o) Direito. Vol. II. Belo Horizonte: Arraes, 2015.

ESTADÃO CONTEÚDO. Bolsonaro não confirma publicação de decreto sobre liberação de trabalhos. 30 mar. 2020. Disponível em: https://exame.abril.com.br/brasil/bolsonaro-naoconfirma-publicacao-de-decreto-sobre-liberacao-de-trabalhos/. Acesso em: 07 de abril de 2020.

FRY, Karin A. Compreender Hannah Arendt. Petrópolis: Vozes, 2017.

GOMES, Pedro Henrique Gomes. Bolsonaro ao responder sobre mortos por coronavírus. Disponível em: https://g1.globo.com/politica/noticia/2020/04/20/nao-sou-coveiro-ta-dizbolsonaro-ao-responder-sobre-mortos-por-coronavirus.ghtml. Acesso em: 30 de julho de 2020.

KANT, Immanuel. Fundamentação da metafísica dos costumes. Portugal: Porto Editora, 1995.

LEIA JÁ. Vereador de Porto Alegre faz meme com morte por covid e é criticado. Disponível em: https://www.leiaja.com/politica/2020/04/06/vereador-de-poa-faz-meme-commorte-por-covid-e-e-criticado/. Acesso em: 30 de julho de 2020.

OLIVEIRA, Luciano. 10 lições sobre Hannah Arendt. 4 ed. Petrópolis: Vozes, 2017.

OXFAM BRASIL. Alerta sobre a responsabilidade pelas mortes evitáveis por Covid-19. Disponível em: https://www.oxfam.org.br/noticias/alerta-sobre-a-responsabilidade-pelasmortes-evitaveis-por-covid-19/. Acesso em: 31 de julho de 2020.

REUTERS. Planalto gasta quase R $\mathbf{5}$ milhões em campanha contra quarentena.

Disponível em: https://noticias.r7.com/brasil/planalto-gasta-quase-r-5-milhoes-em-campanhacontra-quarentena-27032020. Acesso em 07 de abril 2020.

SÁNCHEZ, Cristina. Arendt: a política em tempos obscuros. São Paulo: Salvat, 2015.

SANDEL, Michael J. Justiça: o que é fazer a coisa certa. Rio de Janeiro: Civilização Brasileira, 2017.

SEVERO, Valdete Souto. Sobre a COVID-19 e as nossas escolhas. In.: TOSTES, Anjuli; MELO FILHO, Hugo. Quarentena: reflexões sobre a pandemia. Bauru: Canal 6, 2020.

TRIBUNAL DE JUSTIÇA DE SANTA CATARINA (TJSC). $2^{\text {a }}$ Vara de Fazenda Pública da Comarca de Criciúma. Mandado de Segurança n ${ }^{\circ}$ 5012341-69.2020.8.24.0020/SC. Juiz Pedro Aujor Furtado Junior. Julgamento em: 24 de julho de 2020.

TV GLOBO. RJ estuda protocolo para orientar médicos na decisão de priorizar pacientes por vagas em UTI. Disponível em: https://g1.globo.com/rj/rio-de-janeiro/blog/edimilsonavila/post/2020/05/01/rj-estuda-protocolo-para-orientar-medicos-na-decisao-de-quaispacientes-receberao-leitos-e-respiradores.ghtml. Acesso em: 31 de julho de 2020. 